\title{
Development, Validation and Reliability of a Questionnaire to Assess Awareness, Knowledge, and Practice about Hearing Impairment Among School Teachers
}

Dsouza Angelin Nilisha

Rajesh Ranjan*

\begin{abstract}
Background: Hearing impairment is the most common congenital anomaly. It is well known that teachers are the corner pillar for inclusive education.

Objective: The study aimed to develop a tool that evaluates awareness, knowledge, and practice about Hearing impairment among Teachers and to validate, and test the reliability of the questionnaire.

Methods: A cross-sectional study design and convenient sampling was used to recruit 82 participants. The questionnaire was developed after a familiarity check from Kannada language experts then it was intended for content validation by 6 experts in the field of Audiology. The finalized questionnaire was filled by participants and tested for internal consistency and test-retest reliability.

Results: In the current study finalized questionnaire consisted of 50 questions. The scale content validation index (S-CVI) was shown to be good with $0.944 \mathrm{~S}-\mathrm{CVI}$. The internal consistency showed moderate-good internal consistency in the independent section and very high overall reliability with a value of 0.898 . Further test-retest reliability showed no significant difference $(p>0.05)$ in independent and overall scores of test and retest sessions, respectively. Individual domain and total score intraclass coefficients revealed 'high' test-retest reliability.

Conclusion: The currently developed questionnaire in the Kannada language to assess teachers' awareness, knowledge, and practice about hearing impairment showed high reliability and validity, making it an efficient tool to assess the gaps between regular school teachers on children with hearing impairment.
\end{abstract}

Keywords: KAP (Knowledge, Awareness, Practice), Questionnaire, Teachers, Kannada language, Hearing impairment.

Department Department of Audiology and Speech language Pathology, Kasturba Medical College, Mangalore, Manipal Academy of Higher Education, Manipal, Karnataka, India

Department Department of Audiology and Speech language Pathology, Kasturba Medical College, Mangalore, Manipal Academy of Higher Education, Manipal, Karnataka India, E-mail: rajesh.ranjan@manipal.edu Phone: +91-9480138057

Paper submitted on July 27, 2021; and Accepted on November 15, 2021 


\section{INTRODUCTION}

Proprioceptive Recent figures suggest that in India 6.3\% which is 63 million people are affected by significant hearing loss ${ }^{1}$. The NSSO survey in India showed that per one lakh population 291 persons are currently suffering from hearing impairment from severe- profound ${ }^{2}$. Of these, a great proportion is of children amongst the ages of 0-14 years. Most of them estimate that the prevalence is of nearly 3 million deaf children, in which one in ten deaf children go to school ${ }^{3}$. A report published by World Health Organization ${ }^{4}$ has warned that worldwide every one in four people or 2.5 billion will be living with some level of hearing loss by 2050 unless some efficient action is taken towards early identification and intervention of hearing loss.

It is a known fact that the parents, family members, and health care professionals have the responsibility to early identify hearing impairment in children, yet several cases go unnoticed until they enter the schools because of numerous factors ${ }^{5}$. The untreated hearing problem lead to significant issues in hearing, speech perception, processing, speech-language acquisition, production, which will adversely affect scholastic performance, behavioral, cognitive and psycho-social development ${ }^{6-10}$. As quoted by Marschark ${ }^{11}$, teachers play a critical role in the identification as well as education of children with hearing impairment.

Education of Individual with hearing imapirment have evolved over time, and inclusive education is now given priority due to advancement in hearing technology and rehabilitation method. The teachers play an important role in the hearing-impaired child's educational process to support late identified or early intervened children in the classroom. However, several studies conducted over the years have revealed a lack of knowledge among school teachers around the world ${ }^{12-14}$, including in India ${ }^{15,16}$.

Due to attitude, geography, culture, and language diffrences the available questionnaires may not assess adequately ${ }^{12-14}$. There are no questionnaires available in Indian languages, especially in the Kannada language. The non-standardized questionnaire may not depict the actual situation. If a child with hearing impairment has to be effectively integrated in regular school, we must be able to understand awareness, knowledge, and practice about hearing impairment among school teachers. Therefore the aim of the study was to develop, validate, and test the reliability of the questionnaire in the Kannada language that evaluates awareness, knowledge, and practice about Hearing impairment among Teachers.

\section{MATERIALS AND METHODS}

The current study used a cross-sectional study design and convenient sampling to recruit participants. The Institutional ethics committee approval was taken to carry out the study.

\section{Participants}

A total of 82 teachers participated in the study. Out of them, 77 were female $(93 \%)$ and 5 were male $(7 \%)$ teachers. Before filling the questionnaire, school principals were approached to obtain permission to conduct the study by explaining the significance of the study. The teachers were informed about the study's purpose, need, aim, objective, and significance. The teachers working in regular schools who were teaching $1^{\text {st }}$ to $7^{\text {th }}$ standard were recruited. Teachers who were not proficient in the Kannada Language were excluded from the study. The data was collected from October 2020 to April 2021.

\section{Procedure}

The study was carried out in three phases. The first phase included developing the questionnaire. The second phase included content validating from experts and finalizing the questionnaire. The third phase included testing of internal consistency and test-retest reliability.

\section{Phase 1- Developing the Questionnaire}

To assess teachers' awareness, knowledge, and practice the framework for the questionnaire was designed appropriately in terms of different domains, with different questions under each domain. Based on the literature review a set of questions were constructed in the Kannada Language. The number of questions under each domain is given in Table 1.

The full questionnaire was sent to 2 proficient Kannada Language experts with a Master's or Ph.D. in Kannada Literature and more than 10 years of experience. They examined the suitable language used, grammar, and ease of comprehending of the questionnaire. According to their review and suggestions modification to the questionnaire was done for the further validation process.

\section{Phase 2: Content Validation}

Step 1: Validation of the questionnaire- The reviewed questionnaire was then given to 6 native Kannada experts with Master's or Ph.D. in Audiology and more than 9 years of experience in the feild. The experts were asked to examine whether questions are valid and suitable under each domain. The reviewer was asked to validate the content in the questionnaire using a rating scale depending on its relevance. They were provided with a ' 4 'point rating scale to rate each question, where ' 4 ' denoted an item to be 'extremely valid', and ' 1 'denoted an item to be 'not valid'. The rating scale used for validation is given in table 2. Content validity index $(\mathrm{I}-\mathrm{CVI})$ was calculated for each question as suggested by DeVon et.al ${ }^{17}$ and I- CVI below 0.8 was deleted (Figure 1).

\section{Phase 3: Data Analysis and Reliability Testing}

From the completed questionnaire, responses to each question in each of the five sections were collected and updated in Excel 2019. Every participant's data were dichotomized for correct or incorrect responses, and total and domain scores were divided into good, fair, and poor 
Table 1: Number of questions under each domain

\begin{tabular}{ccc} 
SI. No & Domain & No. of Questions \\
\hline 1. & Demographics & 14 \\
2. & Awareness & 8 \\
3. & Knowledge & 23 \\
4. & Practice & 5 \\
5. & Other & 4 \\
& Total & 54
\end{tabular}

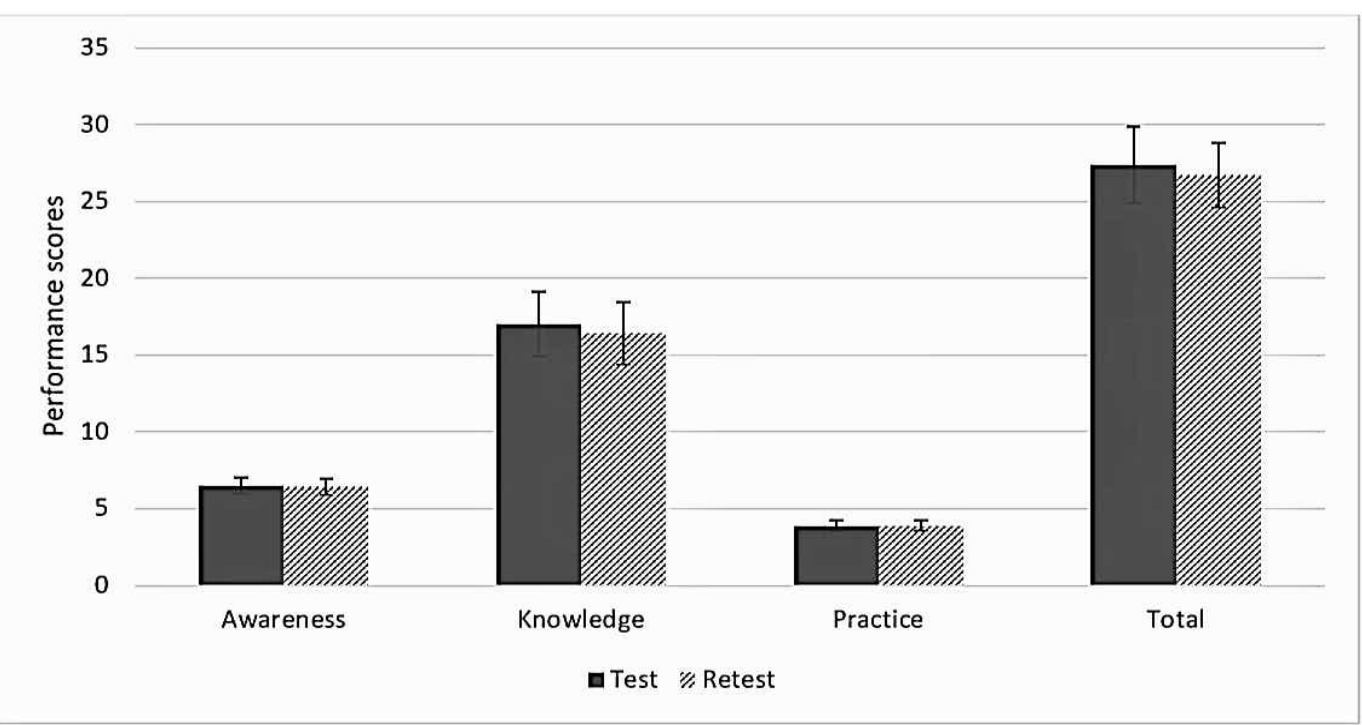

Figure 1: Mean and Standard deviation of individual section and total scores of 'test' and're-test' sessions.

categories. In the awareness domain when the participant chose 'Yes' for each 'True' statement, the response was scored as '1', while 'No' or 'Don't know' was scored as '0'. If the participant chose 'No' for each 'False' statement, the response was scored as '1', while 'Yes' or 'don't know' was scored as ' 0 '. In the awareness section, the scores for 'Good' ranged from 5 to 7, for 'Fair' 3 to 4, and for 'Poor' 2 and below. In the knowledge section, there were multiple choice questions with 5 or 3 options, one of which was the correct response and the other options were incorrect. The selection of the correct option was given a score of ' 1 ', while the incorrect option was given a score of ' 0 '. In the knowledge section, scores for 'Good' ranged from 18 to 27, for 'Fair' from 9 to 17, and for 'Poor' from 8 and below. In the practice section, selecting the correct practice received a score of ' 1 ', while selecting the incorrect practice received a score of ' 0 .' Good scores ranged from 4 to 5 , fair scores from 2 to 3 , and scores of 1 and less were categorized as poor. Total questionnaire scores for 'Good' ranged from 27 to 39, for 'Fair,' from 14 to 26, and for 'Poor,' from 13 and below.

Following that, internal consistency testing and test-retest reliability was performed. For test-retest realibity testing, the questionnaire was administered to 10 participants (12\%), and then re-administered 5 days later. The analysis was carried out using SPSS software version 25.0. The statistical tests which were performed are indicated in Table 3 and 4.

\section{RESULTS}

\section{Content Validation}

Based on the average rating obtained from the 6 Audiologist content validity index (CVI) was calculated. In Table 4,5, 6, and 7 expert rating and content validity index are provided for each domain of the questionnaire. The content validity index (CVI) was calculated using this formula

Content validity index $=\frac{\text { Number of Expert- } \text { Audiologist rated with agreement }}{\text { Total number of Expert- } \text { Audiologists }}$

The validated questionnaire was administered on 82 teachers across 5 domains. The response obtained from the participants of awareness, knowledge, and practice were subjected to testing of internal consistency using Kuder-Richardson-20 (KR-20) formula as they were dichotomous data. The values obtained in internal consistency are given in table 9. Kuder-Richardson-20 (KR-20) coefficient calculated indicated that awareness and knowledge domain had good reliability. While the reliability of the practice domain was moderate as it contained a reduced number of items but the finding was acceptable. Overall reliability of the questionnaire was very high i.e., 0.898, and was shown to be good.

To examine the test-retest reliability of the developed questionnaire, it was first filled out by 10 teachers and then re-administered after 5 days. As the data didn't follow normal distribution Wilcoxon Signed Ranks 
Table 2: Rating scale for validation.

\begin{tabular}{cc}
\hline Scale & Interpretation \\
\hline 4 & Extremely valid \\
3 & Quite valid \\
2 & Somewhat valid \\
1 & Not valid \\
\hline
\end{tabular}

Table 3: Statistical tests used in the study.

Statistical steps

To perform content validation following expert's review To test the internal consistency

To assess the test-retest reliability

\section{Statistical tests used}

Content validation index (17)

Kuder-Richardson Formula 20 (KR- 20)

Wilcoxon signed-rank test and intraclass correlation coefficient (ICC)

Table 4: The expert rating and content validity index of awareness domain questions.

\begin{tabular}{|c|c|c|c|c|c|c|c|c|}
\hline Items & Expert 1 & Expert 2 & Expert 3 & Expert 4 & Expert 5 & Expert 6 & $\begin{array}{l}\text { Number in } \\
\text { agreement }\end{array}$ & Items CVI \\
\hline $\mathrm{A} 1$ & + & - & + & + & + & + & 5 & 0.83 \\
\hline $\mathrm{A} 2$ & + & + & + & + & + & + & 6 & 1 \\
\hline A3 & + & - & - & + & + & + & 4 & $0.66^{\star}$ \\
\hline A4 & + & + & + & + & + & + & 6 & 1 \\
\hline A5 & + & + & + & + & + & + & 6 & 1 \\
\hline A6 & + & + & + & + & + & + & 6 & 1 \\
\hline A7 & + & + & + & + & + & + & 6 & 1 \\
\hline A8 & + & - & + & + & + & + & 5 & 0.83 \\
\hline $\begin{array}{c}\text { Proportion } \\
\text { Relevant }\end{array}$ & 1 & 0.625 & 0.875 & 1 & 1 & 1 & Mean expert $p$ & ortion $=0.916$ \\
\hline
\end{tabular}

Note: Questions with low significance are highlighted and marked with *.

' + ' indicated expert selecting the rating 3 and 4

'-' indicated expert selecting the rating 1 and 2

Table 5: The expert rating and Content validity index of knowledge domain questions.

\begin{tabular}{|c|c|c|c|c|c|c|c|c|}
\hline Items & Expert 1 & Expert 2 & Expert 3 & Expert 4 & Expert 5 & Expert 6 & Number in agreement & Items CVI \\
\hline $\mathrm{K} 1$ & + & + & + & + & + & + & 6 & 1 \\
\hline $\mathrm{K} 2$ & + & - & + & + & + & + & 5 & 0.83 \\
\hline K3 & + & + & + & + & + & + & 6 & 1 \\
\hline K4 & + & + & - & - & + & + & 4 & $0.66^{\star}$ \\
\hline K5 & + & + & + & + & + & + & 6 & 1 \\
\hline K6 & + & + & + & + & + & + & 6 & 1 \\
\hline K7 & + & + & + & + & + & + & 6 & 1 \\
\hline K8 & + & + & + & + & + & + & 6 & 1 \\
\hline K9 & + & + & + & + & + & + & 6 & 1 \\
\hline K10 & - & + & + & + & + & - & 4 & $0.66^{\star}$ \\
\hline K11 & + & + & + & + & + & + & 6 & 1 \\
\hline K12 & + & + & + & + & + & + & 6 & 1 \\
\hline K13 & + & + & + & + & + & + & 6 & 1 \\
\hline K14 & + & + & + & + & + & + & 6 & 1 \\
\hline $\mathrm{K} 15$ & + & + & + & + & + & + & 6 & 1 \\
\hline K16 & + & + & + & + & + & + & 6 & 1 \\
\hline K17 & + & - & + & + & + & + & 5 & 0.83 \\
\hline K18 & + & - & + & + & + & + & 5 & 0.83 \\
\hline K19 & + & + & + & + & + & + & 6 & 1 \\
\hline $\mathrm{K} 20$ & + & + & + & + & + & + & 6 & 1 \\
\hline K21 & + & + & + & + & + & + & 6 & 1 \\
\hline K22 & + & + & - & - & + & + & 4 & $0.66^{\star}$ \\
\hline K23 & + & + & + & + & + & + & 6 & 1 \\
\hline $\begin{array}{l}\text { Proportion } \\
\text { Relevant }\end{array}$ & 0.95 & 0.86 & 0.91 & 0.91 & 1 & 0.95 & Mean expert propc & $1=0.93$ \\
\hline
\end{tabular}

Note: Questions with low significance are highlighted and marked with *.

'+' indicated expert selecting the rating 3 and 4

'-' indicated expert selecting the rating 1 and 2 
Table 6: The expert rating and Content validity index of Practice domain questions.

\begin{tabular}{|c|c|c|c|c|c|c|c|c|}
\hline Items & Expert 1 & Expert 2 & Expert 3 & Expert 4 & Expert 5 & Expert 6 & $\begin{array}{l}\text { Number in } \\
\text { agreement }\end{array}$ & Items CVI \\
\hline $\mathrm{P} 1$ & + & + & + & + & + & + & 6 & 1 \\
\hline $\mathrm{P} 2$ & + & + & + & + & + & + & 6 & 1 \\
\hline P3 & + & + & + & + & + & + & 6 & 1 \\
\hline $\mathrm{P} 4$ & + & + & + & + & + & + & 6 & 1 \\
\hline P5 & + & + & + & + & + & + & 6 & 1 \\
\hline $\begin{array}{c}\text { Proportion } \\
\text { Relevant }\end{array}$ & 1 & 1 & 1 & 1 & 1 & 1 & Mean exper & portion $=1$ \\
\hline
\end{tabular}

Note: Questions with low significance are highlighted and marked with *.

' + ' indicated expert selecting the rating 3 and 4

' - ' indicated expert selecting the rating 1 and 2

Table 7: The expert rating and Content validity index of 'other' domain questions.

\begin{tabular}{|c|c|c|c|c|c|c|c|c|}
\hline Itms & Expert 1 & Expert 2 & Expert 3 & Expert 4 & Expert 5 & Expert 6 & $\begin{array}{l}\text { Number in } \\
\text { agreement }\end{array}$ & Items CVI \\
\hline 01 & + & + & + & + & + & + & 6 & 1 \\
\hline $\mathrm{O} 2$ & + & + & + & + & + & + & 6 & 1 \\
\hline O3 & + & + & + & + & + & + & 6 & 1 \\
\hline $\mathrm{O} 4$ & + & + & + & - & + & + & 6 & 0.83 \\
\hline $\begin{array}{l}\text { Proportion } \\
\text { Relevant }\end{array}$ & 1 & 1 & 1 & 0.75 & 1 & 1 & \multicolumn{2}{|c|}{$\begin{array}{c}\text { Mean expert proportion }= \\
0.95\end{array}$} \\
\hline
\end{tabular}

Note: Questions with low significance are highlighted and marked with *.

' + ' indicated expert selecting the rating 3 and 4

' - ' indicated expert selecting the rating 1 and 2

Table 8: Number of questions in each domain in the final questionnaire.

\begin{tabular}{cccc}
\hline SI. No & Domains & \multicolumn{2}{c}{ No. of questions } \\
\cline { 3 - 4 } & Demographics & Before & 14 \\
2 & Awareness & 14 & 7 \\
3 & Knowledge & 8 & 20 \\
4 & Practice & 5 & 5 \\
5 & Other & 4 & 4 \\
\hline & Total & 54 & 50 \\
\hline
\end{tabular}

Table 9: Internal consistency (reliability) of the questionnaire across domain.

$\begin{array}{cc}\text { Domains } & \text { Kuder-Richardson-20 (KR-20) coefficient } \\ \text { Awareness } & 0.801984 \\ \text { Knowledge } & 0.867548 \\ \text { Practice } & 0.711314 \\ \text { Overall } & 0.898112\end{array}$

Table 10: Test-retest reliability of each domain and overall scores by Wilcoxon Signed Ranks Test.

$\begin{array}{cc}\text { Domains } & \text { 'p' value } \\ \text { Awareness } & 0.317 \\ \text { Knowledge } & 0.083 \\ \text { Practice } & 1.000 \\ \text { Overall } & 0.70\end{array}$

Test was performed to review the findings on total and individual domain scores (awareness, knowledge, practice) obtained from both the test and retest sessions. As shown in table 10 scores in the individual domain and total showed no significant difference $(p>0.05)$.

The mean and standard deviation of the 'domain' and 'total' scores of the test and retest sessions, respectively, are shown in figure 1.

Individual domain and total score intraclass coefficients (ICC) were calculated to further examine test-retest reliability. The results revealed 'high' test-retest reliability (19-21). Table 11 shows the Intraclass coefficient (ICC) determined from test-retest data for each domain and total scores 
Table 11: Intra-class correlation coefficients of test and re-test sessions for each domain and overall scores.

$\begin{array}{cc}\text { Domains } & \text { Intra-class correlation coefficients } \\ \text { Awareness } & 0.899 \\ \text { Knowledge } & 0.812 \\ \text { Practice } & 0.797 \\ \text { Overall } & 0.872\end{array}$

\section{DISCUSSION}

The questionnaire development was initiated by with outline the major sections- Awareness, knowledge, and practice and two additional sections- 'demographics' to know teacher's personal and school information and 'other' section to understand the teacher's opinion on solutions to problems in the education process of hearing-impaired children. The questionnaire initially consisted of 54 questions in total, 36 questions in the main sections and 18 questions in the remaining two additional sections. The questionnaire was then analyzed by two Kannada language experts for familiarity followed by six audiology experts for validation. Content validation revealed that S-CVI was 0.944 , which is considered highly acceptable ${ }^{18}$. According to the item- CVI (I- CVI) results, questions with an I- CVI of 0.8 or higher were kept, while those with an I- CVI of less than 0.8 were excluded.

The final questionnaire consisted of 50 questions. The final questions were of two types- Qualitative and quantitative. The questions under the 'demographics', and 'other' sections were qualitative in nature, they were mainly asked to gather information. However, questions under awareness, knowledge, and practice were quantitative which were either correct or incorrect. The questionnaire used multiple-choice questions. Most of the multiplechoice questions had one correct answer allowed them to obtain independent section and overall scores, and only one question had multiple correct answers and some multiple-choice questions had an option for "other(please mention)" allowing participants to write their response for that question which researchers may not have considered.

Internal consistency of individual major sections ranges from 0.711 to 0.867 , which is greater than the prescribed criterion of $0.70^{18-21}$. According to Gulliksen (1950), the reliability value increases with the length of the test. It's worth noting that the practice section had fewer items than the rest of the sections, which may explain the acceptable but lower internal consistency value comparatively. However, the questionnaire's overall Internal consistency value of 0.898 indicated that it was extremely reliable. Since the 'demographic' and 'other' sections were used for future needs and were not dichotomous or scales, they were not subjected to internal consistency testing.

Test-retest reliability assessed showed no significant differences in each of the independent domains and overall scores were observed $(p>0.05)$. Intra-class coefficients were also used to assess test re-test reliability, this showed high test re-test reliability on subsections and total scores with values being greater than $0.70^{19,20}$. Thus, the developed questionnaire indicated good test re-test reliability overall and for all the independent subsections. There are very few validated and reliable standardized materials to assess teachers' awareness, knowledge, and practice about hearing impairment ${ }^{14-16,22}$. It is important to note that without testing reliability and validation reduces the quality of the tool for further use ${ }^{18}$. Participation of teachers in the developed questionnaire was limited to one district in the state of Karnataka. As a result, the questionnaire's implementation and interpretation must be done cafefully.

\section{CONCLUSION}

The currently developed questionnaire in the Kannada language to assess awareness, knowledge, and practice among regular school teachers about hearing impairment has a good validity index and reliability. This questionnaire can be used as a tool to acknowledge the gaps that may exist among regular school teachers about children with hearing impairment in primary schools.

\section{CONFLICT OF INTEREST}

The authors declares no conflict of interest

\section{REFERENCES}

1. Garg S, Chadha S, Malhotra S, Agarwal AK. Deafness: Burden, prevention and control in India. Natl Med J India. 2009;22:79-81.

2. http://mospi.nic.in/sites/default/files/publication_reports/485_final.pdf

3. https://main.mohfw.gov.in/sites/default/ files/51892751619025258383.pdf.

4. Itoo JA. Hearing impairment at a glance and guidelines for teachers. Int $\mathrm{J}$ Interdisciplinary and Multidisciplinary Studies (IJIMS). 2014;1:145-52.

5. Blamey PJ, Sarant JZ, Paatsch LE, Barry JG, Bow CP, Wales RJ, Wright M, Psarros C, Rattigan K, Tooher R. Relationships among speech perception, production, language, hearing loss, and age in children with impaired hearing. J Speech, Language, and Hearing Res. 2021;44:264-85.

6. Ching TY, Leigh G, Dillon H. Introduction to the Longitudinal Outcomes of Children with Hearing Impairment (LOCHI) study: Background, design, sample characteristics. Int J Audiol. 2013;52:S4-9.

7. Stevenson J, Kreppner J, Pimperton H, Worsfold S, Kennedy C. Emotional and behavioural difficulties in children and adolescents with hearing impairment: a systematic review and meta-analysis. Eur child \& Adolescent Psychiatr. 2015;24:477-96.

8. Theunissen SC, Rieffe C, Netten AP, Briaire JJ, Soede W, Schoones JW, et al. Psychopathology and its risk and pro- 
tective factors in hearing-impaired children and adolescents: A systematic review. JAMA Pediatr. 2014;168:170-7.

9. Daud MK, Noor RM, Abd Rahman N, Sidek DS, Mohamad A. The effect of mild hearing loss on academic performance in primary school children. Int $\mathrm{J}$ pediatr otorhinolaryngol. 2010;74:67-70.

10. Marschark M, Spencer PE, Adams J, Sapere P. Evidencebased practice in educating deaf and hard-of-hearing children: Teaching to their cognitive strengths and needs. European J Special Needs Edu. 2011;26:3-16.

11. Martin FN, Bernstein ME, Daly JA, Cody JP. Classroom teachers' knowledge of hearing disorders and attitudes about mainstreaming hard-of-hearing children. Language, Speech, and Hearing Services in Schools. 1988;19:83-95.

12. Lass NJ, Carlin MF, Woodford CM, Campanelli-Humphreys AL, Judy JM, Hushion-Stemple EA. A survey of classroom teachers' and special educators' knowledge of and exposure to hearing loss. Language, Speech, and Hearing Services in Schools. 1985;16:211-22.

13. AlOtaibi AF, Bashawri HA, AlOtaibi HF, Alqahtani AH, Alzahrani AS, AlOtaibi MS. Knowledge and Attitudes of School Teachers toward Hearing Problems with Students in General Elementary Schools in Makkah, 2019. Med Sci. 2020;24:2900-17

14. Tuli IP, Sarkar A, llapakurty B, Najar IN. Knowledge, Attitude of Sikkim Primary School Teachers About Paediatric Hearing Loss. Indian J Otolaryngol and Head \& Neck Surg. 2018;70:331-6.
15. Verma $\mathrm{H}$, Ravichandran JBA. Awareness, attitude and knowledge about hearing impairment among regular school teachers: Survey across hyderabad. Amity Int J Teacher Edu (AIJTE). 2017;3(1).

16. DeVon HA, Block ME, Moyle-Wright P, Ernst DM, Hayden SJ, Lazzara DJ, et al. A psychometric toolbox for testing validity and reliability. J Nurs scholarship. 2007;39:155-64.

17. Polit DF, Beck CT. The content validity index: are you sure you know what's being reported? Critique and recommendations. Res in Nurs \& Health. 2006;29:489-97.

18. Fink A, Litwin MS. How to measure survey reliability and validity. Sage; 1995.

19. Singh AS, Vik FN, Chinapaw MJ, Uijtdewilligen L, Verloigne M, Fernández-Alvira JM, et al. Test-retest reliability and construct validity of the ENERGY-child questionnaire on energy balance-related behaviours and their potential determinants: the ENERGY-project. Int J Behavioral Nutrition and Phys Activity. 2011;8:1-2.

20. Nunnally JC. Psychometric theory 3E. Tata McGraw-hill education; 1994.

21. Gulliksen H. Theory of Mental Tests. Wiley; 1950.

22. Ward KW, Marx CG, Goshorn E, Turner CG, Bell K. A Survey of K-12 Educators Regarding Awareness of Hearing Loss, Devices and Resources. J Phonet and Audiol. 2015;1:2. 